Article

\title{
Environmental Performance of Noise Reduction System in Cogeneration Plants-A Life Cycle Assessment Study
}

\author{
Andrzej Marcinkowski * and Joanna Kopania
}

Citation: Marcinkowski, A.

Kopania, J. Environmental

Performance of Noise Reduction System in Cogeneration Plants-A Life Cycle Assessment Study. Energies 2021, 14, 1324. https://doi.org/ $10.3390 /$ en14051324

Academic Editor:

Dimitrios Katsaprakakis

Received: 9 February 2021

Accepted: 23 February 2021

Published: 1 March 2021

Publisher's Note: MDPI stays neutral with regard to jurisdictional claims in published maps and institutional affiliations.

Copyright: (c) 2021 by the authors. Licensee MDPI, Basel, Switzerland. This article is an open access article distributed under the terms and conditions of the Creative Commons Attribution (CC BY) license (https:/ / creativecommons.org/licenses/by/ $4.0 /)$.
Faculty of Management and Production Engineering, Lodz University of Technology, 90-924 Lodz, Poland; joanna.kopania@p.lodz.pl

* Correspondence: andrzej.marcinkowski@p.lodz.pl

\begin{abstract}
Although one of the most harmful factors to health is noise, it is often ignored in life cycle assessment (LCA) studies. Most researches regarding noise inclusion in LCA focus on the problem of transport noise, and very few works consider the impact of noise emitted by other sources. This study addresses the effects of noise generated by cogeneration plants. The main objective is to assess the environmental performance of the noise reduction system by considering the health effects of noise due to steam discharge as well as to compare the environmental loss associated with the production and disposal of a steam silencer with the benefits resulting from its application for noise reduction. A method to determine midpoint and endpoint human health indicators for a composition of noise emitted by intermittent stationary source and background noise is developed. The results indicate that the health benefit due to noise reduction is six orders of magnitude greater than the environmental loss. Human health indicators attributable to noise reduction in the residential zones under consideration span a wide range of disability adjusted life years (DALY) - 0.16-136 DALY. The greatest values occur in the densely populated areas located close to the noise source. A formula is proposed to express annoyance of the residents of individual zones depending on their distance to the steam discharge source, its sound power level, and existing background noise level. Uncertainty and sensitivity analyses have been carried out assuming other conditions. Modifications of sound power level, noise reduction efficiency, steam discharge duration, and the silencer lifetime have not affected the overall conclusion drawn.
\end{abstract}

Keywords: combined heat and power plant (CHP); noise silencer; life cycle assessment (LCA); environmental impact; human health impact

\section{Introduction}

A high quality of life demands technologies for energy generation that are not only economically efficient but also effective from environmental and societal point of view. One of the solutions consistent with the sustainable approach is cogeneration technology used in combined heat and power plants (CHP) which enable the combustion of inexpensive fossil fuels to provide satisfactory efficiency thanks to local customers consuming substantial amounts of thermal energy (residential estates, municipal utilities, industrial sectors, etc.). However, high concentrations of people located near the power plant require equipment to reduce the environmental impact of the plant. The application of the equipment is justified if the benefit of the reduction is greater than the loss resulting from its production and disposal.

Besides gas and dust emissions, a significant concern in CHP operation is also noise emission adversely affecting human health and ecosystems. Noise as an environmental pollution with a significant impact on health was identified several decades ago. Sound levels threatening interference with outdoor activities, annoyance, and hearing loss were already known in the 1970s [1]. The results of the conducted research indicate that in Europe noise is the second main cause of health loss, after particulate matter (PM), expressed in 
disability adjusted life years (DALY) [2]. One-third of Europeans are regularly exposed to noise levels above $55 \mathrm{~dB}$ that could significantly damage their health [3]. Despite the longstanding interest of scientists and legislators in the environmental impact of noise, this aspect is still neglected. An important manifestation of this is the lack of noise implementation in the life cycle assessment (LCA) [4,5].

Life cycle assessment, being a tool of environmental management, is a method to evaluate the environmental impact related to products or industrial technologies considering their entire life cycle. The method allows one to take into account the environmental burden resulting from the particular elements of the supply chain from the extraction of resources necessary for the production of analyzed objects to their disposal. LCA also considers different impact categories that comprise the contribution of the materials applied to the depletion of natural resources, the impact of industrial activities on ecosystem quality, and effects of the emitted pollution on human health. The standard describing principles and framework for life cycle assessment [6] indicate the necessity of introducing noise in the impact assessment analyses, however, this is not common practice due to the lack of established procedures and insufficient advancement level of the proposed models. A limited number of researches attempting to incorporate noise effects on human health in the life cycle assessment have been published so far, despite noise inclusion potentially changing the results of many LCA studies already available [7]. Moreover, most of the works published in this field focus on the problem of noise emitted by transport. There are very few studies representing a more general approach to take into account the impact of noise emitted by other sources. Efforts made over the last two decades to introduce a noise category in life cycle impact assessment (LCIA) framework failed to achieve a satisfactory consensus [8]. Consequently, noise data are not included in LCA databases such as ecoinvent [9].

One of the first attempts to determine noise LCIA indicator was presented by Steen $[10,11]$. The author adopted a monetization approach using willingness to pay (WTP) and willingness to accept (WTA) values to analyze the impact of transport noise on human health. Noise effects were limited only to nuisance, defined as a noise level above $65 \mathrm{~dB}$, however some indirect effects on morbidity and mortality were perceived. Considering a rush hours ratio (4/24), and assuming an average fuel consumption $(1 \mathrm{~kg} / 10 \mathrm{~km})$, the characterization factor $(\mathrm{CF})$ was determined $\left(2.53 \times 10^{-5}\right.$ person-years/vehicle $\left.\mathrm{km}\right)$. The major drawback of this model is a simplification assuming that $25 \%$ of the global population is exposed to noise levels above $65 \mathrm{~dB}$, that was determined basing on the average percentage for cities in Western Europe (10-20\%) and Central and Eastern Europe (up to $50 \%$ ). Another disadvantage is that the CF is expressed in a unit which is not compatible with DALY which is a widely used unit of health damage.

The other method to assess the environmental impact associated with transport noise was presented by Müller-Wenk [12-14]. The procedure accounted a cause-effect chain, linking noise level due to a single vehicle with the final health impairment. For the development of the damage assessment stage, the author adopted the concept used in case of chemical emissions analyses which consisted of four modules:

- Fate analysis-reflecting the increase of the toxic substance concentration in the environment due to the emission of a specific amount of pollutant,

- Exposure analysis-describing the number of people affected by concentration increase,

- Effect analysis-determining the incremental effect of a certain concentration increase during a specific period on human health,

- Damage analysis - expressing the total magnitude of health damage.

The health impairment midpoint indicator was expressed in number of cases of communication disturbance (during daytime) and sleep disturbance (during nighttime) which could be converted into an aggregable endpoint indicator expressed in DALY. The human damage indicators were determined given the noise level increment due to additional transport, various vehicle classes, number of people exposed to certain background noise levels, and time of the day. The model made a significant contribution to 
the field; however, it presented some disadvantages as well. The number of people exposed to the considered noise level changes was determined based on Zurich data extrapolated to the total Swiss population, thus the method needed more data to be applicable to other countries. Moreover, the fate analysis procedure used in the model could only distinguish between two types of vehicles: light (including cars, vans, light motorcycles) and heavy (including trucks, buses, tractors, heavy motorcycles) [15]. Similarly, the effect analysis was based on outdated surveys carried out in 1991 [16]. The method was later improved by Doka [17], using a more advanced noise emission model, called SonRoad [18]. Further improved possibility to differentiate between vehicle types was provided by Althaus et al. [19,20] who integrated SonRoad model with data from Steven [21].

Another relevant improvement of the model was presented by Franco et al. [22]. The authors pointed out that a linearity assumption in the incremental approach of noise impact assessment leads to neglecting the effects of baseline noise due to the logarithmic nature of noise levels, and consequently, to a substantial overestimation of noise level resulting from an additional traffic. An alternative attribution scheme considering background noise to improve accuracy of noise level increments determination was then proposed. The polynomial approximations of the dose-response curves by Miedema and Oudshoorn [23], later included in an official European guidance [24], were applied to calculate the number of highly annoyed persons (HAP), reflecting health impairment relating to the noise exposure. However, the model does not provide for aggregation of the output in DALY unit. Modification of this model was presented by Moliner et al. [25]. In order to assess background noise level, noise maps were used in the study. The health effects of noise were quantified in DALY, allowing for the comparison of the impact of noise produced by heavy vehicles with impacts due to fuel consumption and air emissions caused by the vehicle. The results showed that noise was the third-most significant impact category in terms of damage to human health, which justified its inclusion in the LCA model.

A more general model was proposed by Cucurachi et al. $[7,26]$. The aim of the studies was to provide a framework for the inclusion in the LCA the impact on human health of any type of noise (not limited to transportation noise). As the noise level unit, $d B$, does not allow for an aggregation over the life cycle due to its logarithmic characteristics, the developed model expressed the noise emission in joules $(\mathrm{J})$ of sound energy, which was obtained by integrating the sound power of the source (W) over time (s). Sound energy amounts were processed separately depending on the frequency of the sound wave (eight octave bands were adopted) and different compartments (e.g., urban area, daytime; urban area, nighttime; rural area, daytime; etc.). Finally, the characterization factor was expressed in person $\cdot \mathrm{Pa} \cdot \mathrm{s}$, reflecting the number of people exposed to a certain sound pressure during a certain time. The model was not completed in detail, since the authors identified a number of missing elements of the whole framework. The method was then compared to others by Meyer et al. [27] in case studies concerning car tires. The results of the conducted analyses implied that the approach proposed by Cucurachi and Heijungs [26] led to an overestimation of the impact by a few orders of magnitude. The drawbacks of this approach (lack of possibility to compare the noise impact with health effects due to other air emissions) was also noticed by Ongel [28] who set up her own framework aimed at modeling road traffic noise in life cycle inventory (LCI) and developing an LCIA method allowing for the comparison of health impacts of noise with other transport-related emissions. The presented effect analysis applied the doseresponse polynomial approximations developed by Miedema and Oudshoorn [23], Babisch et al. [29], and Miedema et al. [30] to account the health impacts associated with annoyance, acute myocardial infarction, and sleep-disturbance, respectively. The applicability of the proposed method was illustrated using a case study quantifying the health impact of transport noise in 9 Istanbul municipalities. The results obtained (3830 DALY per year corresponding to 0.1 DALY per average person over a lifetime) were finally compared with total European emission of PM10, ammonia, nitrogen oxides, sulfur dioxide, and non-methane volatile organic compounds [31]. The impact of noise corresponded to $40 \%$ 
of health effects due to other air emission considered. The author also perceived that the LCA perspective requires accounting not only noise generated by running vehicles but also noise emitted by vehicle manufacturing, road construction, energy production, etc. However, there are no data currently available for the assessment of health impacts due to exposure to industrial or construction noise. Missing life cycle perspective was raised by Heijungs and Cucurachi [32]. Moreover, they considered this approach more as a site-specific noise assessment rather than a general method that allowed for the application in various locations.

The recent contributions in the field of noise inclusion in LCA were presented by Meyer [33] and Meyer et al. [8]. The proposed method combined the advantages of models existing earlier. The authors applied the procedure consisting of the following five steps:

- Definition of the noise characterization model,

- Choosing the reference flow for noise in LCI,

- Selecting the impact midpoint in LCIA,

- Choosing the LCIA modeling perspective,

- Computation of the characterization factors (CF).

As a propagation model, the NMPB 2008 method [34] distinguishing two types of vehicles was chosen. The dose-response polynomial approximations proposed by Miedema et al. $[23,30]$ were applied to determine the percentage of highly annoyed people (HAP), and highly sleep-disturbed people (HSDP), respectively, defining the daytime as 6 a.m.-10 p.m. and nighttime as 10 p.m. -6 a.m. In total, two approaches were tested to calculate the midpoint CFs: the distance-based approach and energy-based approach. Despite most existing LCIA methods being based on the marginal modeling (representing consequential thinking), the study also applied the average approach (representing attributional thinking) to compare their sensitivity with respect to variations of the initial traffic. The presented case study involved the use of map of population exposure to noise which had been elaborated according to the requirement for European cities under the European Directive, 2002/49/EC [35]. The analyzed area (a part of Lyon metropolitan area, France) was divided into 67 territory units covering $39 \mathrm{~km}^{2}$, with population of over 176,000 people. $\mathrm{CF}$ values calculated for each area separately differed significantly from each other by around two orders of magnitude. The differences of CFs were explained by the variation of population density and sound energy density occurring in individual areas. The mean $\mathrm{CF}$ values weighted by magnitude of the elementary traffic under consideration were proposed as an approximation for practical use. As the case study concerned an urban area where the population density was greater than 1000 inhabitants $/ \mathrm{km}^{2}$, the application of the obtained results to rural areas would require replication of the approach for areas with low population density. For the further development of $\mathrm{CF}$, the energy-based approach was recommended, as in order to take account of the noise characteristics of new vehicle types, the distance-based approach would demand a more sophisticated emission model.

Another recent study aimed at determining the noise footprint of personal mobility in Switzerland [5]. The model included land-based transportation distinguishing between private cars, regional, urban and long-distance trains, trams, and trolley buses considering the distances covered and speeds. The CNOSSOS method [36] was used to compute the sound power level. The midpoint score (expressed in person $\cdot \mathrm{Pa} \cdot \mathrm{s}$ ) was determined given various archetypes, differentiating frequencies within the frequency spectrum of 36-8000 Hz. The endpoint indicator (in DALY unit) was also obtained using a conversion factor. Following a consumption-based perspective the noise footprint for individual Swiss municipalities was determined and illustrated in the map of Switzerland with different colors representing footprint ranges. The results implied that road mobility contributed most to the overall noise footprint of land transport. A huge potential of total noise footprint reduction (by $55 \%$ ) was identified by an additional scenario assuming full transition to an electric fleet.

In the existing literature, dedicated to noise inclusion in the LCA, most studies concern exclusively noise due to transport. In a few works a small fraction of attention was paid 
to other sources of noise, e.g., [7,8]. Majority of the studies attempting to include noise impact into LCA, use polynomials converting noise level into midpoint indicator such as percentage of highly annoyed persons (HAP). For the case of industrial sources of noise, analogous relationships were determined by Miedema and Vos [37]. However, the results were based on a much smaller data sample compared to the data set from which similar relationships were derived for transportation noise. The field studies were conducted at 11 locations only (one seasonal industry, two shunting yards, eight other industries), which could have caused significant inaccuracies. The differences between the percentage of HAP calculated for seasonal industry and shunting yards reached 30 percentage points at noise level (Lden) $55 \mathrm{~dB}$, and 47 percentage points at $65 \mathrm{~dB}$. Thus, the estimates of the polynomials parameters, especially for the seasonal industry and shunting yards, were only indicative with no recommendation for use in other research. Generally, the state of the art of industrial noise impact assessment needs further development. At the current stage, researchers and practitioners addressing stationary noise sources can take advantage of achievements made in a related area concerning traffic noise.

Among the most particular stationary noise sources with regard to the specificity and parameters of the emitted sound are the steam discharges from power plants. Due to the high pressures of process steam, the boilers start up and blow down steam superheaters, and the activation of the safety valves cause noise emissions of a very high intensity. The noise level can reach $140 \mathrm{~dB}$, considerably exceeding the maximum permissible sound level of intermittent noise. The noise of this magnitude is the most bothersome when it is produced by combined heat and power plants since they are often located in a densely populated areas of large towns. Their location in urban-industrial centers allow the CHP to achieve a higher fuel efficiency through cogeneration, but it intensifies the human health effects due of noise, as during steam discharge the level of sound may rise by 30-40 dB within a radius of a few kilometers [38]. Since the heat demand varies throughout the year, depending on the outside temperature, some boilers of cogeneration plants are operated seasonally. Such a time frame makes it necessary to start up the peak demand boilers every year at the beginning of the heating season. During the pre-heating process, high pressure steam is discharged into the air causing a high-level noise for a few days.

The most effective method to reduce noise emitted by steam discharges from power plant boilers is the installation of noise silencers on the discharge pipes. The devices are made of several coaxially mounted cylinders filled with a noncombustible, nonhygroscopic, sound-absorbing material that is protected by a glass fiber cloth or perforated metal sheets [39]. Due to aggressive operating conditions associated with high temperature steam flow, stainless steel as well as enamel coatings are applied. Thus, an additional environmental impact of the product life cycle is involved to minimize the human health effects due to noise, that may be considered as a kind of pollution transfer. To verify the environmental justification that steam discharge silencers use, an LCA analysis could be employed. Therefore, the main aim of this study is to assess the environmental performance of the noise reduction system considering health effects of noise due to steam discharge as well as to compare the benefit resulting from the noise reduction with the environmental loss associated with a steam silencer production within a site-specific case study. Given there are no clear guidelines on how to include industrial noise impact in the LCIA stage, to achieve the objective it is necessary to develop a method allowing for the quantification of the health damage of a particular stationary intermittent industrial noise.

The studies aiming to include noise in the LCA are still being conducted. Their main objective is to develop a method for noise effects quantification that would be consistent with widely used methods for determining environmental impact of air emission of chemical substances. The researchers test various propagation and exposure models. Their results imply that the obtained indicators strongly depend on local conditions (noise intensity, population density).

In the following section of this paper a method to quantify the health damage of an intermittent industrial noise is proposed. The section 'Results and discussion' presents 
the application of the method to determine noise effects due to steam discharge by CHP. The results of the baseline scenario are discussed considering findings of uncertainty and sensitivity analyses. The main conclusion is presented in the last section.

\section{Materials and Methods}

The life cycle assessment method was standardized, and the principles and requirements are specified by the International Organization for Standardization [6,40]. According to the standards, the LCA framework consists of four main stages: goal and scope definition, life cycle inventory (LCI), life cycle impact assessment (LCIA), and interpretation. In this study, the former three stages are included in the Section 2 while the latter is presented in the Section 3.

\subsection{Goal and Scope Definition}

The main aim of the analysis was to propose a method to assess the health effects of noise emitted by steam discharge from a cogeneration plant boiler with and without the equipment to reduce sound level as well as to compare the results with a human health indicators of steam silencer production and disposal. The functional unit was defined as one item of an industrial steam discharge noise silencer. A model of the device is based on a real type of the noise silencer designed and manufactured by Thermal Technology Branch "ITC" in Lodz, Poland. Durability of the equipment was assumed for $t_{S}=10$ years. An acoustic reduction efficiency of the assumed device was $30 \mathrm{~dB}$ which is a typical performance of steam noise silencers [41]. The proposed method adopted a marginal approach considering the existing environmental noise level and determined the impact of an incremental increase of noise due to the steam discharge. Although noise is emitted within the entire product life cycle (including resources extraction processes, transportation, raw material processing, etc.), in this study only noise occurring during operation phase was considered. The diagram illustrating the scope of the analysis was depicted in Figure 1. The subsequent stages represent the environmental impact mainly due to mines and processing plants, silencers manufacturer's processes (cutting, drilling, welding, enameling), use of the silencer for noise reduction (device operation), and material recycling (waste disposal), respectively.

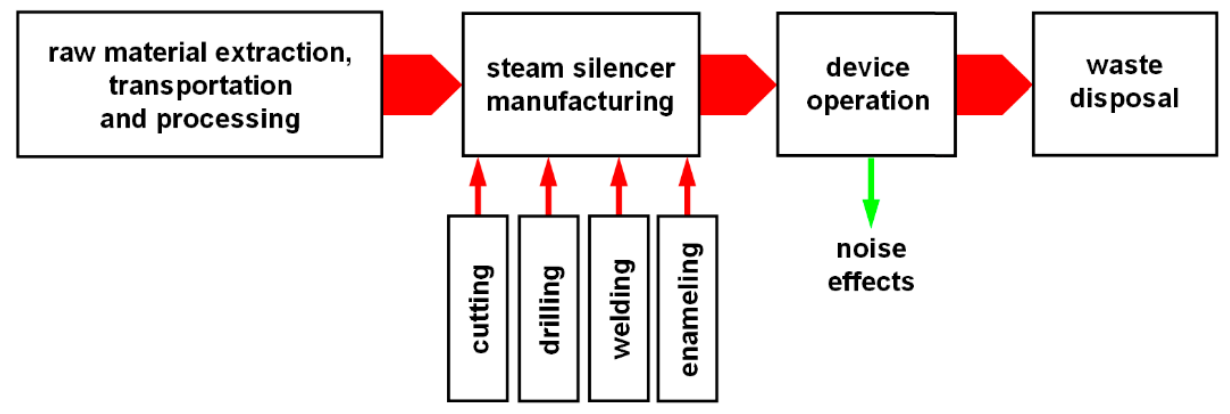

Figure 1. The scope of the analysis.

\subsection{Life Cycle Inventory}

The steam silencer inventory was based on the manufacturer data. The relevant raw materials were steel sheets $(134 \mathrm{~kg})$, chromium steel $(36.7 \mathrm{~kg})$, minor steel products $(0.5 \mathrm{~kg})$ as well as glass wool fabric $(0.6 \mathrm{~kg})$. Manufacturing processes involved steel cutting (consuming $40 \mathrm{kWh}$ of electricity), drilling (producing $22.3 \mathrm{~kg}$ of scrap iron), welding $(17.4 \mathrm{~m})$ including argon use $(0.5 \mathrm{~kg})$, and enameling $\left(4.8 \mathrm{~m}^{2}\right)$. Data concerning industrial noise due to steam discharge were based on on-site measurements. The location of the industrial noise source was cogeneration plant EC-3 which is the greatest power plant in Lodz (Poland), operating eight boilers with total electric power exceeding $200 \mathrm{MW}$. The device analyzed was designed for a given discharge pipe situated $41 \mathrm{~m}$ above ground level. The measured sound power level of the noise source LSSP was $148 \mathrm{~dB}$. 


\subsection{Life Cycle Impact Assessment}

A framework comprising four steps was adopted in this study for the life cycle impact assessment stage: propagation analysis, exposure analysis, effect analysis, and damage analysis.

The propagation of noise due to steam discharge was determined according to European Directive [35] by means of SON2 5.31, Eko-Soft, Poznan, Poland. The computation output was provided in the form of spatial distribution (nine isophones) of A-weighted nominal level of noise due to steam discharge $L_{S \text {-nom-isophon }}$ given coordinates of the sound source, data concerning buildings situated around the source (height, length, location, orientation, wall material) and types of the ground surfaces. The noise level in individual points $L_{S \text {-nom(i) }}$ situated between subsequent isophones $(i$ and $i+1)$ was determined as logarithmic mean (Equation (1)). For the case of noise reduction by steam silencer, the assumed noise levels for individual isophones $L_{S \text {-nom-isophon }}$ were assumed to be $30 \mathrm{~dB}$ lower [41].

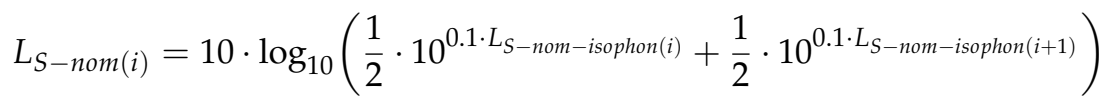

The day-evening-night noise level was determined by Equation (2) [42].

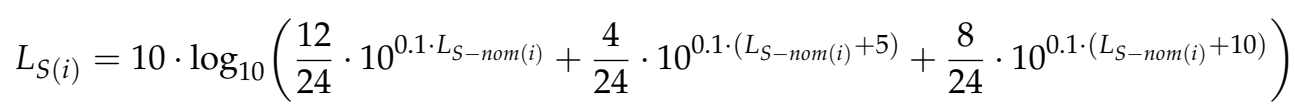

As the marginal approach was adopted by the model, the existing environmental noise level was also considered. The source of background noise level was the Acoustic map of the city of Lodz for 2017-2022 [43] that was developed according to European Directive [35]. The map depicted A-weighted equivalent day-evening-night noise levels in the form of isophones $L_{B-i s o p h o n}$. The noise level in individual points $L_{B(j)}$ situated between subsequent isophones $(j$ and $j+1$ ) was determined as logarithmic mean (Equation (3)).

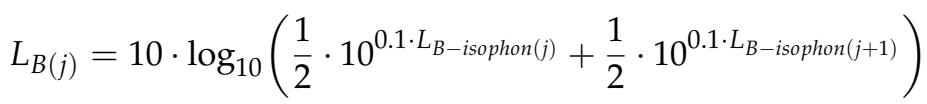

The spatial range of noise exposure- the northern part of Lodz and the town's suburbs, with an area of $74 \mathrm{~km}^{2}$ and population of over 280,000-was divided into 144 zones of three types: residential areas (92), industrial zones (24), and greenery (28). The zone division was presented in Figure 2. Noise exposure was considered only in residential zones and classified as noise-protected areas. Population of individual zones $P_{(z)}$ was estimated taking into account data on statistic living conditions in Lodz [44], as well as number, size and type of residential building distinguishing: detached houses, low multifamily buildings, four- to five-storey blocks of flats and tall (usually 11-storey) residential buildings. The estimation method was verified comparing the determined numbers of inhabitants with the official population of the analyzed town district. The borders of demarcated zones were overlapped on acoustic maps of noise level due to steam discharge (Figure 3), and background noise level mainly represented by traffic (Figure 4). 


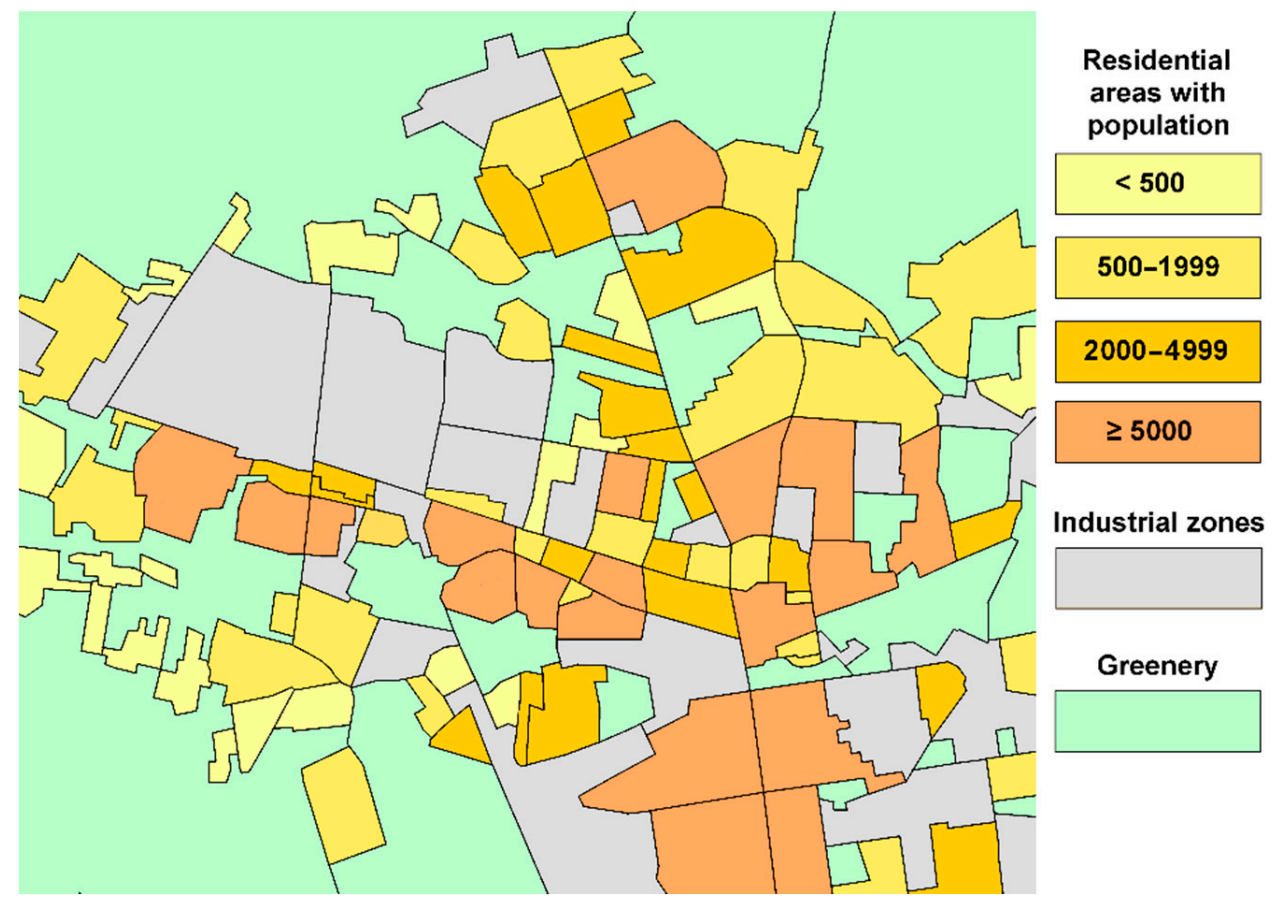

Figure 2. The division of exposed area into zones and population of residential areas.



Figure 3. Noise level due to the steam discharge without a silencer use. 


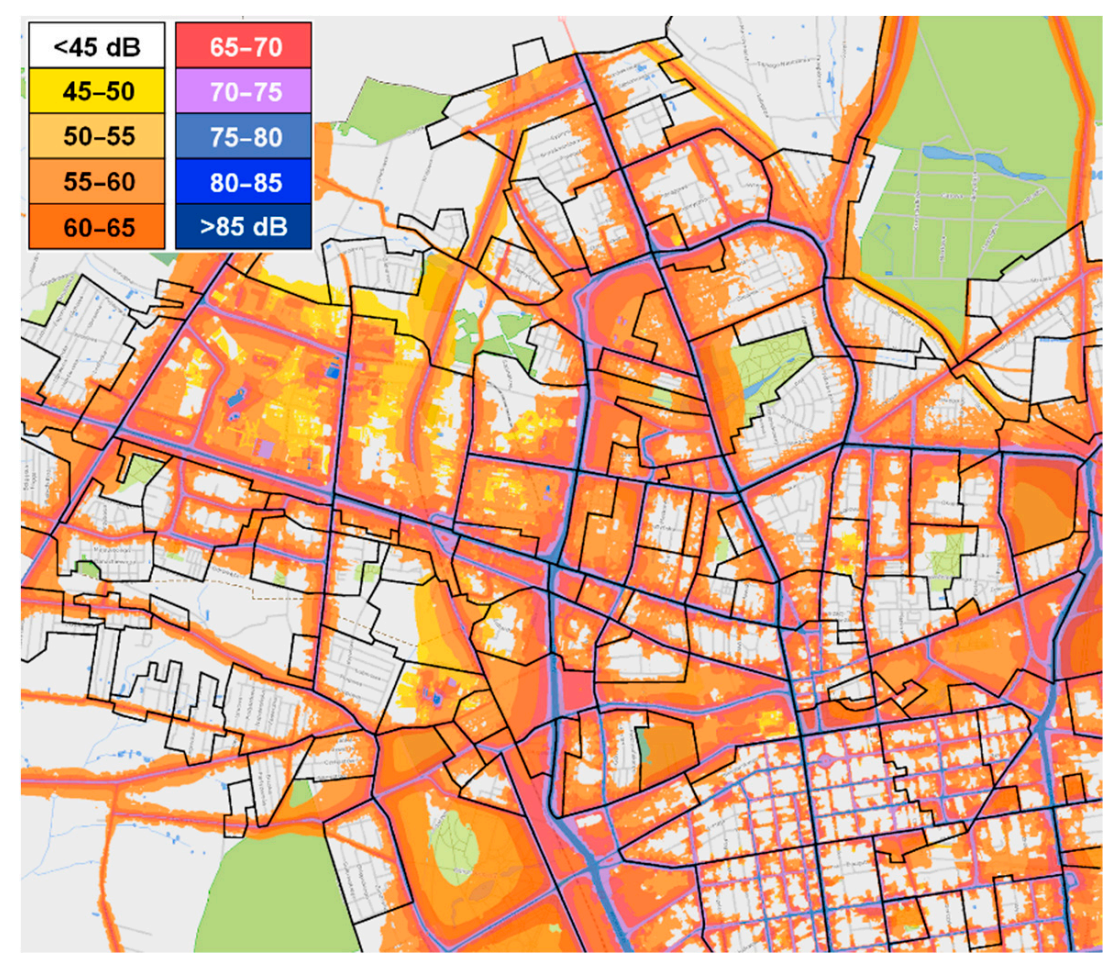

Figure 4. The background noise level.

In order to estimate the number of inhabitants exposed to noise of a given level, a visual assessment of the share of the areas corresponding to each of eight particular noise levels $L_{B(j)}$ in the total area of the analyzed zones was made. As a result, 736 subzones with a specific area share $S_{(z)(j)}$ (ranging from $0 \%$ to $100 \%$ ) and different background noise levels were distinguished. The same procedure was applied to determine the share of the areas affected by each of the nine particular noise levels $L_{S(i)}$ due to steam discharge $S_{(z)(j)(i)}$. Population of individual zones $P_{(z)(j)(i)}$ were calculated by (Equation (4))

$$
P_{(z)(j)(i)}=P_{(z)} \cdot S_{(z)(j)} \cdot S_{(z)(j)(i)}
$$

For each subzone a momentary noise level was determined as a logarithmic sum of background noise and noise due to steam discharge:

$$
P_{(z)(j)(i)}=P_{(z)} \cdot S_{(z)(j)} \cdot S_{(z)(j)(i)}
$$

To be able to capture the intrinsic complexity of noise impact on human health, this study followed the known practice in the field to base a midpoint characterization on annoyance assessment [8]. Thus, the increase of the number of highly annoyed people $\triangle H A P$ resulting from the additional noise due to steam discharge was used as the midpoint indicator. The percentage of highly annoyed people $(\% H A P)$ was calculated using the polynomial approximation developed by Miedema and Oudshoorn [23] for traffic noise (Equation (6)), and the relationship by Miedema and Vos [37] for industrial noise emitted by stationary source (Equation (7)). Since both formulas are valid for 45-75 dB, for noise levels outside of the range, boundary values were assumed: $45 \mathrm{~dB}$ for $L_{d e n}<45 \mathrm{~dB}$ and $75 \mathrm{~dB}$ for $L_{\text {den }}>75 \mathrm{~dB}$.

$$
\begin{array}{r}
\% H A P_{\text {road }}\left(L_{\text {den }}\right)=9.868 \cdot 10^{-4} \cdot\left(L_{\text {den }}-42\right)^{3}-1.436 \cdot 10^{-2} \cdot\left(L_{\text {den }}-42\right)^{2}+0.5118 \cdot 10^{-4} \cdot\left(L_{\text {den }}-42\right) \\
\% H A P_{\text {industry }}\left(L_{\text {den }}\right)=36.307-1.886 \cdot L_{\text {den }}+0.02523 \cdot L_{\text {den }}{ }^{2}
\end{array}
$$


As the background noise was represented mainly by road traffic, Equation (6) was used to determine the percentage of HAP due to background noise. However, during a steam discharge the cumulative noise had two components: traffic and industrial. In order to consider a different character of noise emitted by various sources, noise with the prevailing level was taken into account while determining HAP percentage. The definition of the noise level was used, which indicates that twice the sound pressure is represented by a noise level $3 \mathrm{~dB}$ higher. Thus, if the aggregated noise level was more than $3 \mathrm{~dB}$ higher than the background level (difference between the total noise level $L_{T(z)(j)(i)}$ and background noise level $L_{B(z)(j)}$ was greater than $3 \mathrm{~dB}$ ), the cumulative noise was assumed to have an industrial character, and consequently, Equation (7) was applied, otherwise, Equation (6) was used assuming that the traffic noise dominated in the cumulative noise composition (see Equation (8)).

$$
\Delta \% H_{A} P_{(z)(j)(i)}=\left\{\begin{array}{c}
L_{T(z)(j)(i)}-L_{B(z)(j)(i)} \leq 3 d B: \% H A P_{\text {road }}\left(L_{T_{365}(z)(j)(i)}\right)-\% H A P_{\text {road }}\left(L_{B(z)(j)}\right) \\
L_{T(z)(j)(i)}-L_{B(z)(j)(i)}>3 d B: \% H A P_{\text {industry }}\left(L_{T_{365}(z)(j)(i)}\right)-\% H A P_{\text {road }}\left(L_{B(z)(j)}\right)
\end{array}\right.
$$

where $L_{T 365(z)(j)(i)}$ represents the total equivalent noise level taking into account the duration time of steam discharge noise emission $t_{N E}$ related to the whole year, according to Equation (9).

$$
L_{T_{365}(z)(j)(i)}=10 \cdot \log _{10}\left(10^{0.1 \cdot L_{B(z)(j)}}+\frac{t_{N E}}{365} 10^{0.1 \cdot L_{S(z)(j)(i)}}\right)
$$

The number of highly annoyed people $\triangle H A P$ resulting from the additional noise due to steam discharge attributable to one year was computed for all zones together by Equation (10).

$$
\Delta H A P=\sum_{z=1}^{92} \sum_{j=1}^{8} \sum_{i=1}^{9} P_{(z)(j)(i)} \cdot \frac{\Delta \% H A P_{(z)(j)(i)}}{100}
$$

To allow for the comparison of the environmental impact resulted from noise with health effects associated with other cycle stages of the product life, the damage analysis was carried out. The endpoint human health indicator $(\mathrm{HH})$ expressed in DALY was calculated using Equation (11). The indicator reflects the health impact related to the functional unit including the assumed silencer lifetime $t_{S}$. Following the suggestion of WHO [45], the disability weight $(D W)$ was assumed on the level of 0.02 . To enable graphical presentation of the results, Equation (12) was used to calculate the indicators specific for individual zones $H H_{(Z)}$.

$$
\begin{gathered}
H H=D W \cdot t_{S} \cdot \Delta H A P \\
H H_{(Z)}=D W \cdot t_{S} \cdot \sum_{i}^{8} \sum_{j}^{9} P_{(z)(j)(i)} \cdot \frac{\Delta \% H A P_{(z)(j)(i)}}{100}
\end{gathered}
$$

The environmental impacts of industrial processes (extraction, processing, drilling, welding, etc.) associated with the life cycle of the noise reduction equipment were determined using the Ecoinvent 2.2 database [46]. The ReCiPe method involving procedures given European conditions (Europe ReCiPe H/A) was applied to determine human health endpoint indicators (exclusive of noise impact), using SimaPro software. Since the main material of the silencer is steel, recycling has been assumed as the product post-life stage being the most probable scenario.

\section{Results and Discussion}

The method presented here was used to analyze the baseline scenario in Section 3.1. Then, the impact of the assumed conditions on the obtained results was examined in Section 3.3. 


\subsection{Baseline Scenario}

The annual health damage due to the background noise assessed in terms of HAP by Equation (6) varies across the analyzed zones ranging from 2.4 to 2241 which corresponds to a range of $0.5-448$ DALY per functional unit. The total health effect for the entire area under consideration, calculated by Equation (12), reaches 5884 DALY. Figure 5a presents the analyzed zones with the graphical representation of the human health indicator increase $\left(\mathrm{HH}_{(\mathrm{Z})}\right)$ over the background level resulting from the additional noise due to steam discharge without a silencer use. The indicators range is $0.16-136$ DALY. The greatest values occur in the zones located relatively close to the noise source and having high population. The zones situated within the $65 \mathrm{~dB}$ and $60 \mathrm{~dB}$ isophones of $L_{S}$ noise level (pink and purple lines in Figure 5a) located within circular areas with a diameter of approximately 4.4 and $6.4 \mathrm{~km}$, represent $62 \%$ and $87 \%$ of total $H_{(\mathrm{Z})}$ sum, respectively. The total $H H$ indicator reaches 2218 DALY. Figure $5 \mathrm{~b}$ shows $\mathrm{HH}_{(\mathrm{Z})}$ indicator increase over the background level resulting from the additional steam discharge noise assuming the silencer application. The range of the indicator is $0.0-8.1$ DALY reflecting a considerable reduction of human health impact due to steam discharge. The majority of the noise health effects, $98 \%$, is observed in the subzones located inside the isophon representing the $L_{S}$ noise level of $40 \mathrm{~dB}$ (blue line in Figure 5b). Over a half of the impact is attributable to 3 of 92 zones. The total $\mathrm{HH}$ indicator is 36.7 DALY which corresponds to the decrease in health damage due to silencer application by 2181 DALY. Thus, the silencing equipment provided $98 \%$ reduction of stationary noise effects and $27 \%$ reduction of impact due to cumulative noise. A juxtaposition of midpoint and endpoint indicators corresponding to the background and steam discharge noise are presented in Table 1.

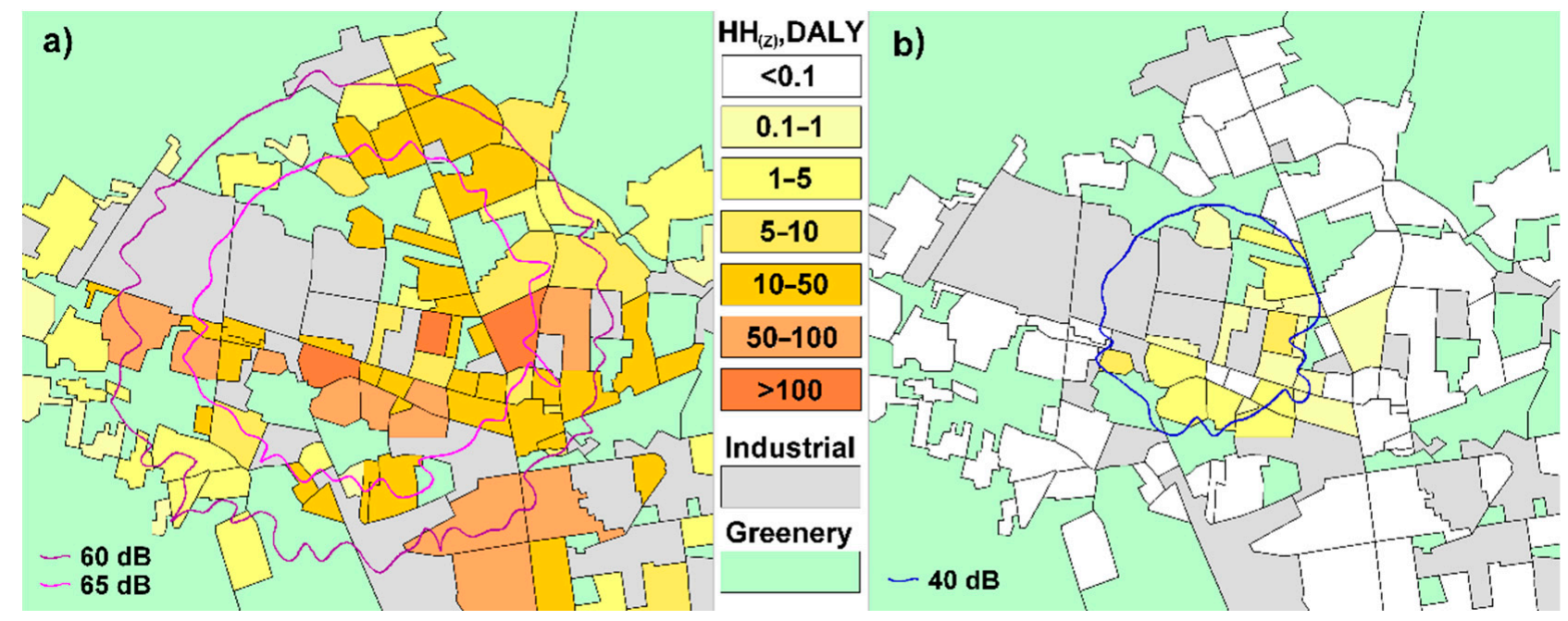

Figure 5. Endpoint indicator increase resulting from noise due to steam discharge, (a) without the silencer use, (b) with the silencer use.

The efficiency of the noise impact reduction in different zones varies depending on the noise level to which inhabitants of individual areas are exposed. The distribution of $H_{(Z)}$, and the efficiency of its reduction over various noise levels is depicted in Figure 6. For $L_{S}<75 \mathrm{~dB}$, steam discharge silencer provided reduction with the efficiency of $100 \%$ as the noise level has been decreased to less than $45 \mathrm{~dB}$. The resulting $L_{S}$ is negligible in relation to the average weighted background noise level of approximately $65 \mathrm{~dB}$. In case of $L_{S}>75 \mathrm{~dB}$, the efficiency of $\mathrm{HH}_{(\mathrm{Z})}$ reduction is significantly below $100 \%$ and decreases with increasing $L_{S}$ ranging from 83 to $97 \%$. The greatest drop in $H H_{(Z)}$ is observed for $L_{S}>80 \mathrm{~dB}$, however, the share of this range in total $\mathrm{HH}$ reduction is relatively low (10 DALY representing $0.4 \%$ ) as there are only few zones exposed to such high noise levels. The highest share of $H H_{(Z)}$ reduction occurs in subzones with middle steam discharge noise level, most notably for the 
$L_{S}$ range of $60-75 \mathrm{~dB}$ that represents $1674 \mathrm{DALY}$ accounting for $76 \%$ of total $\mathrm{HH}$ reduction. In case of the lowest $L_{S}<60 \mathrm{~dB}$, health impact reduction is less significant (13\% of total $H H)$, as the discharge noise level is below the average background noise level.

Table 1. Total midpoint and endpoint human health indicators associated with background and steam discharge noise.

\begin{tabular}{ccc}
\hline Noise Sources & $\begin{array}{c}\text { Midpoint Human Health } \\
\text { Indicator (HAP/year) }\end{array}$ & $\begin{array}{c}\text { Endpoint Human Health } \\
\text { Indicator (DALY) }\end{array}$ \\
\hline Background & 29,420 & 5884 \\
Background + steam discharge without the silencer & 40,508 & 8102 \\
Background + steam discharge with the silencer & 29,603 & 5921 \\
Steam discharge without the silencer (excluding background) & 11,088 & 2218 \\
Steam discharge with the silencer (excluding background) & 184 & 36.7 \\
Reduction due to the silencer & 10,905 & 2181 \\
\hline
\end{tabular}

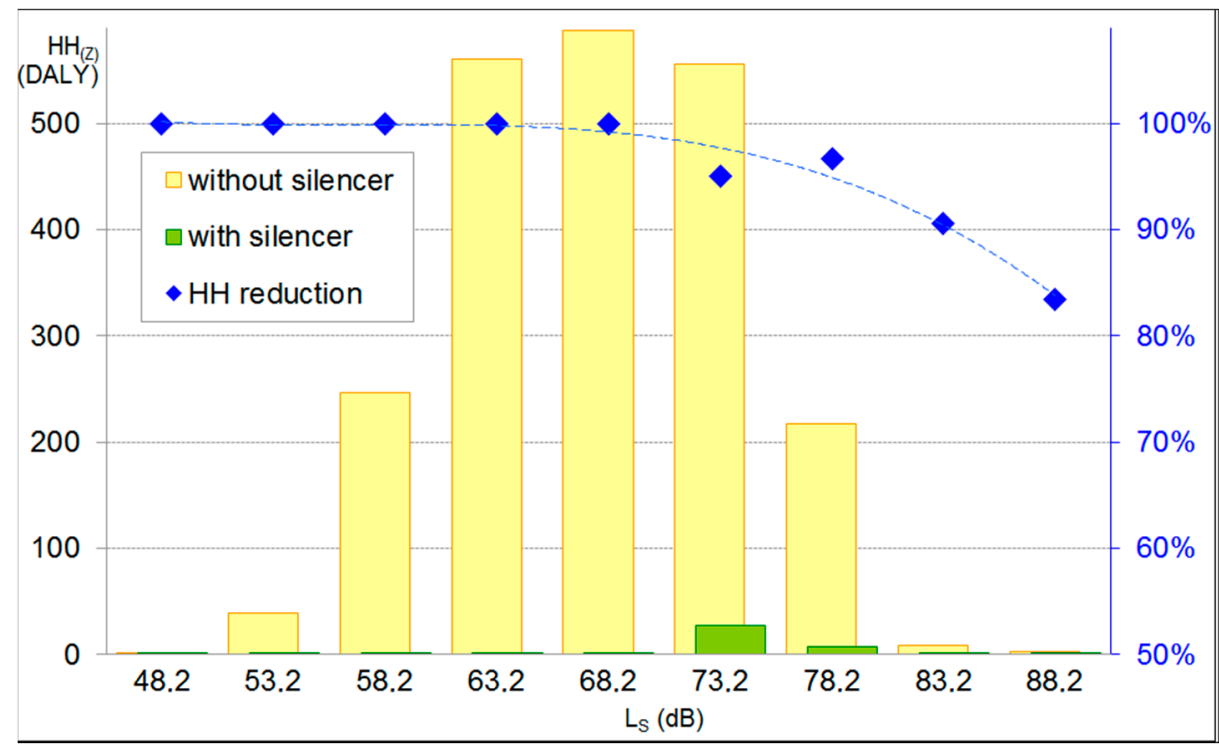

Figure 6. The distribution of the $H H$ indicator over various $L_{S}$ noise levels.

The determined $H H_{(Z)}$ indicators span a very wide range 0.81-679 HAP (corresponding to $0.16-136$ DALY) depending on the noise background level in individual zones and their exposure to steam discharge noise. Substantial differences in results (up to 10 orders of magnitude) depending on various local conditions were previously presented by Ongel [28]. The lowest CFs were obtained in case of municipalities with the highest population density which was explained by lower noise levels due to lower traffic speeds in more congested areas. A wide range of results was also reported by Mayer et al. [8] in their research concerning the heath impact of traffic noise. For the different territorial units of Lyon metropolitan area, the authors have obtained a characterization factor ranging $2.09 \cdot 10^{-6}-1.16 \cdot 10^{-4}$. Considerable differences were even observed between results for areas located close to each other. A large part of the CF distribution was explained by the variation of population density and sound energy density. To avoid questioning the pertinence and feasibility of the method, characterization factors weighted by the magnitude of the elementary traffic was suggested as a good approximation from a statistical point of view.

Since the results of this study indicate perceivable spatial dependence, a model is proposed aiming at describing characterization indicators depending on selected variables. Thus, it has been noted that the steam discharge noise level $L_{S}$ attributed to a certain zone is correlated with sound power level $L_{S S P}$ of the noise source and the distance $R$ between the 
noise source and the zone under consideration. To express this relationship, a formula has been developed using the empirical data within the $R$ range of $0.6-5.7 \mathrm{~km}$ (Equation (13)).

$$
L_{S}=\left(L_{S S P}-42.8\right)-30.9 \cdot R^{\frac{1}{3}}
$$

Based on Equation (13), another three-parameter correlation has been developed allowing to estimate the percentage of highly annoyed people \%HAP (Equation (14)).

$$
\% H A P=A \cdot L_{S}^{B} \cdot L_{B}{ }^{C}
$$

where: $L_{S}$-steam discharge noise level calculated by Equation (13); $L_{B(Z)}$-an average background noise level for an individual zone; $A=6.3 \times 10^{-6} ; B=4.4 ; C=-1.2$.

The Equation (14) provides correlation coefficient of 0.962 , whereas the mean relative error is below $10 \%$. The midpoint indicator represented by the number of highly annoyed people $(\triangle H A P)$ can be obtained by multiplication of \%HAP calculated with Equation (14) and population of the considered zone, and consequently, the endpoint indicator may be determined using Equation (11).

The determined reduction of endpoint human health indicator (2181 DALY) allows to compare the benefit resulted from the silencer use with the environmental burden of the device production stage. Having considered the material extraction, processing, and assembling of the silencer, the endpoint characterization indicators have been computed and are presented in Table 2. The total human health indicator equals 0.00135 DALY including the effect of steel sheet production as the process with a predominant environmental impact. Since steel recycling has been assumed as the product post-life scenario, the disposal stage provides a significant reduction (44\%) of the impact. As a result, the endpoint characterization indicator amounts to 0.000759 DALY, representing the total environmental loss, which is more than six orders of magnitude less than the indicator reflecting the human health benefit due to the application of the noise reduction device. The relation confirms the relevance of noise effects among other environmental aspects.

\begin{tabular}{|c|c|c|c|}
\hline \multirow[b]{2}{*}{ Impact Category } & \multicolumn{3}{|c|}{ Endpoint Characterization Indicator (DALY) } \\
\hline & Production & Disposal & Total \\
\hline Climate change Human Health & $8.58 \times 10^{-4}$ & $-3.06 \times 10^{-4}$ & $5.52 \times 10^{-4}$ \\
\hline Ozone depletion & $5.26 \times 10^{-8}$ & $-8.53 \times 10^{-9}$ & $4.41 \times 10^{-8}$ \\
\hline Human toxicity & $1.30 \times 10^{-4}$ & $-5.60 \times 10^{-5}$ & $7.41 \times 10^{-5}$ \\
\hline Photochemical oxidant formation & $6.43 \times 10^{-8}$ & $-2.81 \times 10^{-8}$ & $3.62 \times 10^{-8}$ \\
\hline Particulate matter formation & $3.63 \times 10^{-4}$ & $-2.31 \times 10^{-4}$ & $1.32 \times 10^{-4}$ \\
\hline Ionizing radiation & $1.40 \times 10^{-6}$ & $-1.78 \times 10^{-7}$ & $1.32 \times 10^{-4}$ \\
\hline sum: & $1.35 \times 10^{-3}$ & $-5.93 \times 10^{-4}$ & $7.59 \times 10^{-4}$ \\
\hline
\end{tabular}

Table 2. Endpoint characterization indicators computed for the silencer production and disposal.

\subsection{Uncertainty Analysis}

The specificity of the proposed method involves the visual assessment of the population of individual zones as well as area shares attributed to various noise levels $L_{S}$ and $L_{B}$. The relative difference between the population determined by the referred method and official number of inhabitants in the analyzed district does not exceed $2 \%$. This inaccuracy affects the final results proportionally, as population is a factor in Equation (10). For the visual assessment of area shares, a 5\% resolution was adopted. The potential error resulting from this uncertainty is limited as all the shares always summed up to $100 \%$. The least favorable situation, leading to an excessively high $\mathrm{HH}$, may occur when the share of the lowest $L_{B}$ is underestimated by $5 \%$, and, consequently, the share of the highest $L_{B}$ in the same zone is overestimated. This effect of result disruption can be even increased if accompanied by overestimation and underestimation of the area shares of the highest and the lowest $L_{S}$, respectively. A simulation assuming such an adverse situation has 
been carried out to assess the impact of such errors made in all the residential zones on final results. The obtained deviations are shown in the Table 3. Overestimation of $L_{S}$ and simultaneous underestimation of $\mathrm{L}_{\mathrm{B}}$ caused the increase of reduction of $\mathrm{HH}$ indicator by $6.6 \%$. The opposite situation has also been analyzed, assuming overestimation of area share attributed to $L_{B}$ and underestimation of area share attributed to $L_{S}$. As shown in the last column of Table 3, the obtained $H H$ indicators are lower by $6.4 \%$ compared to baseline results.

Table 3. The deviation of $H H$ indicators due to potential errors in the assessment of area shares attributed to various noise levels $L_{S}$ and $L_{B}$.

\begin{tabular}{cccc}
\hline Scenario & $\begin{array}{c}\text { Baseline } \\
\text { Scenario }\end{array}$ & $\begin{array}{c}\text { Overestimation of } \boldsymbol{L}_{\boldsymbol{S}} \\
\text { and Underestimation of } \boldsymbol{L}_{\boldsymbol{B}}\end{array}$ & $\begin{array}{c}\text { Overestimation of } \boldsymbol{L}_{\boldsymbol{B}} \\
\text { and Underestimation of } \boldsymbol{L}_{\boldsymbol{S}}\end{array}$ \\
\hline HH without the silencer (DALY) & 2218 & 2370 & 2069 \\
HH with the silencer (DALY) & 36.7 & 46.0 & 28.1 \\
HH reduction (DALY) & 2181 & $2324(+6.6 \%)$ & $2041(-6.4 \%)$ \\
\hline
\end{tabular}

Apart from the noise effects, the remaining silencer life cycle stages (production and disposal) could also introduce uncertainties to the health damage impact assessment. Thus, Monte Carlo simulations were applied to generate 95\% confidence intervals for determined midpoint indicators. The intervals are depicted with a blue line in Figure 7. As the indicators range exceeds five orders of magnitude, the values in Figure 7 are presented in logarithmic scale. The highest uncertainties (exceeding 200\%) occur in case of Ionizing radiation, however the indicator magnitude of this category is relatively low, thus its contribution to the overall uncertainty is negligible. The greatest share in total human health effects results from the Climate change category which indicates a confidence interval within $-10 \%$ to $+12 \%$. Given total human health impact (see the bottom bar in Figure 7) a confidence interval comprises a range of $\pm 22 \%$.



Figure 7. Confidence intervals for total human health indicator in relation to its components.

\subsection{Sensitivity Analysis}

The presented method to assess the health damage due to steam discharge noise includes a number of assumptions that may affect the obtained results. The aim of this section is to analyze the sensitivity of the results to the changes in baseline scenario conditions such as sound power level, acoustic reduction efficiency, industrial noise duration, and the silencer lifetime. 
The sound power level of the source of noise due to steam discharge $L_{S S P}$ was assumed to be $148 \mathrm{~dB}$, basing a direct measurement. However, in case of boilers of other types $L_{S S P}$ may be different. In order to determine the endpoint $\mathrm{HH}$ indicators for different noise source sound power levels, additional analyses have been carried out resulting in the relationship illustrated in Figure 7. General tendency clearly shows that the human health effect of steam discharges substantially increases as the $L_{S S P}$ level rises. The growth of the sound power level to $158 \mathrm{~dB}$ increases the endpoint indicator more than two times, while decreasing the $L_{S S P}$ to $138 \mathrm{~dB}$ and $128 \mathrm{~dB}$ reduces the human health impact by $54 \%$ and $85 \%$, respectively. However, lower sound power level enhances the $H H$ reduction (see blue points in Figure 8), as it is easier to prevent health effects in case of lower noise levels. Despite the considerably lower $H H$ indicator for $L_{S S P}=128 \mathrm{~dB}$ compared to the baseline sound power level of $148 \mathrm{~dB}$, the difference between the environmental benefit (333 DALY) and damage resulting from the silencer production (0.00135 DALY) still contains five orders of magnitude.

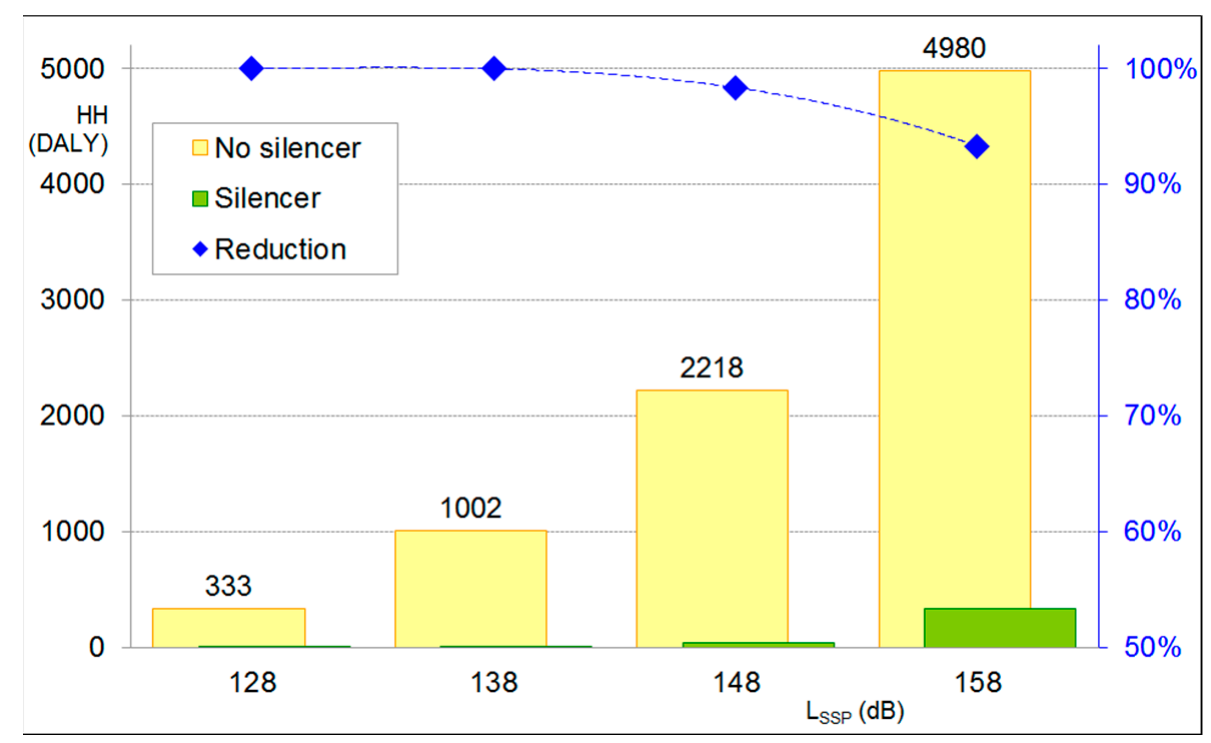

Figure 8. $H H$ indicator for various sound pressure levels of the noise source $L_{S S P}$.

The baseline scenario assumed that the silencer reduced the sound power level of the steam discharge by $30 \mathrm{~dB}$. Supplementary simulations have been performed to provide the results for other acoustic reduction efficiencies presented in Table 4. As in case of $30 \mathrm{~dB}$ efficiency the reduction in $\mathrm{HH}$ indicator reached 98\%, no considerable increase in $\mathrm{HH}$ reduction can be expected for higher silencer efficiency ( $35 \mathrm{~dB})$. There is also no substantial difference in results for the silencing efficiency decreased by $5 \mathrm{~dB}$, the $H H$ reduction is worse only by $3 \%$ compared to the baseline scenario. In case of the lowest efficiency $(20 \mathrm{~dB})$, the difference is more significant reaching $13 \%$.

Table 4. Human health indicator for different acoustic reduction efficiencies of the silencer.

\begin{tabular}{cccccc}
\hline \multirow{2}{*}{ Scenario } & Unit & \multicolumn{4}{c}{ Acoustic Reduction Efficiency, dB } \\
& & $\mathbf{2 0}$ & $\mathbf{2 5}$ & $\mathbf{3 0}$ & $\mathbf{3 5}$ \\
\hline HH without the silencer & DALY & & & 2218 & \\
HH with the silencer & DALY & 333 & 122 & 36.7 & 6.5 \\
HH reduction & DALY & 1884 & 2096 & 2181 & 2211 \\
& $\%$ & 85 & 95 & 98 & 100 \\
\hline
\end{tabular}

During the boiler pre-heating process in CHP plants, high pressure steam is discharged, emitting noise for a few days. As in the baseline scenario, the process was assumed to last for 2 days, however additional analyses have been conducted assuming 
steam discharge duration $t_{N E}$ ranging for 0.5-8 days. The results depicted in Figure 9 show non-linear relationship between $\mathrm{HH}$ indicator and noise emission time. Doubling the duration time $t_{N E}$ causes the $H H$ indicator to increase by $15-27 \%$. Despite substantial differences in the steam discharge duration, the human health effect ranks in the same order of magnitude, and the silencer noise reduction efficiency remains at the same level of 98-99\%.

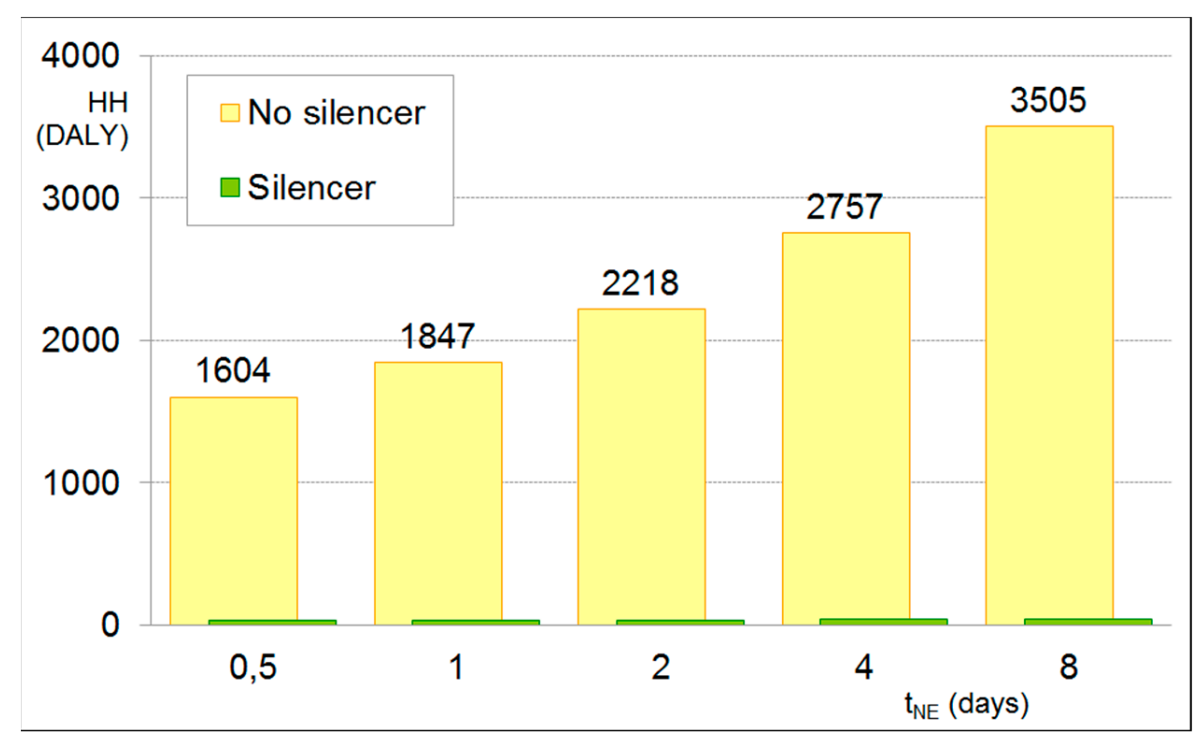

Figure 9. The relationship between $\mathrm{HH}$ indicator and steam discharge duration time.

The silencer lifetime $t_{S}$ is another relevant parameter of the adopted model. Since directly associated with the device durability, it contributes significantly to the functional unit definition. The device lifetime was assumed in baseline scenario for 10 years. The relationship between the endpoint human health indicator $\mathrm{HH}$ and the silencer durability $t_{S}$ is linear, as it is one of the factors in Equation (11). The longer the device lifetime, the greater the environmental benefits resulting from noise reduction. Increasing the life span of a silencer requires the use of more durable materials for its production, reducing the environmental performance of the production phase. However, the relation between human health benefits and losses, exceeding six orders of magnitude, points out that from an environmental perspective, it is worth to take such a material change into consideration. A supplementary simulation assuming the noise silencer production using chromium steel as the main material indicates over two times greater effect on human health (0.0027 DALY) compared to baseline scenario result.

The magnitude of health damage resulting from the device production may be dependent on the chosen LCIA method. In the baseline scenario, Europe ReCiPe H/A method has been used. Direct comparison of endpoint indicators provided by various methods is not possible, as some methods do not support conversion of midpoint results into indicators expressed in DALY. Thus, the most common midpoint categories related with human health (climate change/global warming and ozone depletion) have been considered to compare the results of different methods. Table 5 presents the midpoint indicators obtained using the most popular LCIA methods as well as endpoint indicators calculated using conversion factors sourced from the baseline scenario. Regardless of the method, the results are essentially the same, where only insignificant differences within a fraction of a percent are observed between the figures. 
Table 5. Midpoint and endpoint indicators obtained using various life cycle impact assessment (LCIA) methods.

\begin{tabular}{ccccc}
\hline LCIA Method & $\begin{array}{c}\text { Climate Change } \\
\mathbf{( k g ~ C O}_{\mathbf{2}} \text { eq) }\end{array}$ & $\begin{array}{c}\text { Ozone Depletion } \\
\text { (kg CFC-11 eq) }\end{array}$ & $\begin{array}{c}\text { Endpoint } \\
\text { (DALY) }\end{array}$ & $\begin{array}{c}\text { Relative } \\
\text { Difference }\end{array}$ \\
\hline ReCiPe H/A & $3.94 \times 10^{2}$ & $1.88 \times 10^{-5}$ & $5.52 \times 10^{-4}$ & - \\
CML 2001 & $3.94 \times 10^{2}$ & $1.73 \times 10^{-5}$ & $5.53 \times 10^{-4}$ & $+0.08 \%$ \\
TRACI 2 & $3.94 \times 10^{2}$ & $1.90 \times 10^{-5}$ & $5.53 \times 10^{-4}$ & $+0.09 \%$ \\
IMPACT 2002+ & $3.93 \times 10^{2}$ & $1.90 \times 10^{-5}$ & $5.51 \times 10^{-4}$ & $-0.20 \%$ \\
EDIP 2003 & $3.95 \times 10^{2}$ & $1.87 \times 10^{-5}$ & $5.54 \times 10^{-4}$ & $+0.27 \%$ \\
\hline
\end{tabular}

\section{Conclusions}

The objective of this study was to compare the health benefits resulting from the reduction a steam discharge noise with the environmental burden associated with the production and disposal of noise silencers, providing the noise reduction considered. The literature review revealed that efforts made to introduce noise category in LCA method failed to achieve a satisfactory consensus. As most studies in this field focused on the human health effects of traffic noise it was necessary to develop a method to quantify the environmental impact of the particular stationary intermittent industrial noise and analyze its application to a specific case study. The development of the method was based on achievements in the field of the traffic noise impact assessment.

Contrary to the case of a human toxicity of an emitted substance where a fixed characterization factor is determined to reflect its effect on human health, in the analyzed case study, the determined $\mathrm{HH}$ indicators associated with noise emission span a very wide range depending on the location, population and background noise level specific for individual zones. A correlation Equation (14) was proposed to express the relationship between a percent of highly annoyed people in a particular zone and its distance to the noise source, and existing background noise level. The equation provided a high correlation coefficient of 0.962 .

Comparison of the health effects attributed to noise reduction and the noise silencer manufacturing indicated considerable differences in results. The environmental benefit exceeded the loss by six orders of magnitude which confirms the significant contribution of noise in total balance of the environmental impact. This conclusion was not invalidated by the results of the sensitivity analysis carried out. Additional simulations assuming other conditions by modifying sound power level, noise reduction efficiency, steam discharge duration and a silencer lifetime also indicated that the human health benefit is higher than the negative health effect by a few orders of magnitude.

Having concluded a substantial human health impact of steam discharge noise, it should be stressed that, considering the baseline scenario conditions, the health effect due to background noise was even greater. A reason was the continuous character of traffic noise that affected town residents on a daily basis at approximate noise level of $65 \mathrm{~dB}$ whereas the steam discharge had an intermittent character with duration of a few days a year. To meet the same magnitude of a human health burden, the sound power level of the industrial noise source would have to reach $160 \mathrm{~dB}$.

Author Contributions: Conceptualization, A.M. and J.K.; methodology, A.M.; software, A.M. and J.K.; investigation, A.M.; resources, J.K.; writing-original draft preparation, A.M.; visualization, A.M. All authors have read and agreed to the published version of the manuscript.

Funding: This research received no external funding.

Institutional Review Board Statement: Not applicable.

Informed Consent Statement: Not applicable.

Data Availability Statement: Not applicable.

Conflicts of Interest: The authors declare no conflict of interest. 


\section{References}

1. US Environmental Protection Agency. Information on Levels of Environmental Noise Requisite to Protect Public Health and Welfare with an Adequate Margin of Safety; EPA: Washington, DC, USA, 1974.

2. Stansfeld, S.A. Noise Effects on Health in the Context of Air Pollution Exposure. Int. J. Environ. Res. Public Health 2015, 12, 12735-12760. [CrossRef] [PubMed]

3. Roovers, C.; van Blokland, G.; Psychas, K. Road Traffic Noise Mapping on a European Scale. In Proceedings of the 29th International Congress and Exhibition on Noise Control Engineering InterNoise 2000, Nice, France, 27-30 August 2000; Cassereau, D., Ed.; Volume 6, pp. 3587-3590.

4. Stewart, J.; McManus, F.; Rodgers, N.; Weedon, V.; Bronzaft, A. Why Noise Matters: A Worldwide Perspective on the Problems, Policies and Solutions; Routledge: Abington, UK, 2011.

5. Cucurachi, S.; Schiess, S.; Froemelt, A.; Hellweg, S. Noise footprint from personal land-basedmobility. J. Ind. Ecol. 2019, 23, 1028-1038. [CrossRef]

6. International Organization for Standardization. ISO 14044: 2006, Environmental Management_Life Cycle Assessment-Requirements and Guidelines; International Organization for Standardization: Geneva, Switzerland, 2006.

7. Cucurachi, S.; Heijungs, R.; Ohlau, K. Towards a general framework for including noise impacts in LCA. Int. J. Life Cycle Assess 2012, 17, 471-487. [CrossRef] [PubMed]

8. Meyer, R.; Benetto, E.; Mauny, F.; Lavandier, C. Characterization of damages from road traffic noise in life cycle impact assessment: A method based on emission and propagation models. J. Clean Prod. 2019, 231, 121-131. [CrossRef]

9. Wernet, G.; Bauer, C.; Steubing, B.; Reinhard, J.; Moreno-Ruiz, E.; Weidema, B. The ecoinvent database version 3 (part I): Overview and methodology. Int. J. Life Cycle Assess. 2016, 21, 1218-1230. [CrossRef]

10. Steen, B. A Systematic Approach to Environmental Priority Strategies in Product Development (EPS): Version 2000—General System Characteristics; Chalmers University of Technology: Goteborg, Sweden, 1999.

11. Steen, B. A Systematic Approach to Environmental Priority Strategies in Product Development (EPS): Version 2000—Models and Data of the Default Method; Chalmers University of Technology: Goteborg, Sweden, 1999.

12. Müller-Wenk, R. Life-Cycle Impact Assessment of Road Transport Noise; Universität St. Gallen: St. Gallen, Switzerland, 1999.

13. Müller-Wenk, R. Attribution to Road Traffic of the Impact of Noise on Health. Int J. Life Cycle Assess. 2002, 7, 376. [CrossRef]

14. Müller-Wenk, R. A method to include in lca road traffic noise and its health effects. Int J. Life Cycle Assess. 2004, 9, 76-85. [CrossRef]

15. SAEFL. Strassenlarmmodell für überbaute Gebeite. Swiss Agency for Environment, Forest and Landscape; SAEFL: Bern, Switzerland, 1991.

16. Oliva, C. Belastungen der Bevolkerung durch Flug und Strassenlarm; Duncker \& Humblot: Berlin, Germany, 1998.

17. Doka, G. Ergänzung der Gewichtungsmethode für Ökobilanzen Umweltbelastungspunkte'97 zu Mobilitäts-UBP'97; Doka Ökobilanzen: Zurich, Switzerland, 2003.

18. Heutschi, K. SonRoad: New Swiss road traffic noise model. Acta Acust. United Acust. 2004, 90, 548-554.

19. Althaus, H.J.; De Haan, P.; Scholz, R.W. A methodological framework for consistent context-sensitive integration of noise effects from road transports in LCA. Part 1. Requirement profile and state-of-science. Int. J. Life Cycle Assess. 2009, 1, $218-220$.

20. Althaus, H.J.; De Haan, P.; Scholz, R.W. Traffic noise in LCA: Part 2: Analysis of existing methods and proposition of a new framework for consistent, context-sensitive LCI modeling of road transport noise emission. Int. J. of Life Cycle Assess. 2009, 14, 676-686. [CrossRef]

21. Steven, H. Ermittlung der Geräuschemission von Kfz im Straßenverkehr; TÜV Nord: Würselen, Germany, 2005.

22. Franco, V.; Garraín, D.; Vidal, R. Methodological proposals for improved assessments of the impact of traffic noise upon human health. Int. J. Life Cycle Assess. 2010, 15, 869-882. [CrossRef]

23. Miedema, H.M.E.; Oudshoorn, C.G.M. Annoyance from Transportation Noise: Relationships with Exposure Metrics DNL and DENL and Their Confidence Intervals. Environ. Health Perspect 2001, 109, 409-416. [CrossRef] [PubMed]

24. European Communities. Position Paper on Dose Response Relationships between Transportation Noise and Annoyance; Office for Official Publications of the European Communities: Luxembourg, 2002.

25. Moliner, E.; Vidal, R.; Franco, V.; Garraín, D. A Method to Assess the Impact of Road Transport Noise within the Framework of Life Cycle Assessment. DYNA Ingenieria Industria 2013, 1, 1-12.

26. Cucurachi, S.; Heijungs, R. Characterisation factors for life cycle impact assessment of sound emissions. Sci. Total Environ. 2014, 468, 280-291. [CrossRef] [PubMed]

27. Meyer, R.; Benetto, E.; Igos, E.; Lavandier, C. Analysis of the different techniques to include noise damage in life cycle assessment. A case study for car tires. Int. J. Life Cycle Assess. 2017, 22, 744-757. [CrossRef]

28. Ongel, A. Inclusion of noise in environmental assessment of road transportation. Environ. Model. Assess. 2016, 21, 181-192. [CrossRef]

29. Babisch, W. Road traffic noise and cardiovascular risk. Noise Health 2008, 10, 27-33. [CrossRef] [PubMed]

30. Miedema, H.M.E.; Passchier-Vermeer, W.; Vos, H. Elements for a Position Paper on Night-Time Transportation Noise and Sleep Disturbance TNO Inro Report 2002-59; Netherlands Organization for Applied Scientific Research: Delft, The Netherlands, 2002.

31. Van Zelm, R.; Huijbregts, M.A.J. European characterization factors for human health damage of PM10 and ozone in life cycle impact assessment. Atmos Environ. 2008, 42, 441-453. [CrossRef] 
32. Heijungs, R.; Cucurachi, S. Life Cycle Assessment of Noise Emissions: Comment on a Recent Publication. Environ. Model. Assess. 2017, 22, 184. [CrossRef]

33. Meyer, R. Development of Time-Dependent Characterisation Factors for Life Cycle Impact Assessment of Road Traffic Noise on Human Health. Human Health and Pathology. Ph.D. Thesis, Université de Cergy Pontoise, Cergy-Pontoise, France, 10 November 2017.

34. Besnard, F.; Le Duc, E. Road Noise Prediction 2-Noise Propagation Computation Method Including Meteorological Effects (NMPB 2008); SETRA: Bagneux, France, 2009.

35. The European Parliament and of the Council. Directive 2002/49/EC of 25 June 2002 Relating to the Assessment and Management of Environmental Noise; The European Parliament and of the Council: Brussels, Belgium, 2002.

36. Kephalopoulos, S.; Paviotti, M.; Ledee, F.A. Common Noise Assessment Methods in Europe (CNOSSOS-EU); Publications Office of the European Union: Luxembourg, 2012.

37. Miedema, H.M.E.; Vos, H. Noise annoyance from stationary sources: Relationships with exposure metric day-evening-night level (DENL) and their confidence intervals. J. Acoust Soc. Am. 2004, 116, 334-343. [CrossRef] [PubMed]

38. Tupov, V.B.; Chugunkov, D.V. Noise Silencers on Discharge Lines of Steam from Power-Generating Boilers. Therm. Eng. 2009, 56, 660-664. [CrossRef]

39. Zroichikov, N.A.; Prokhorov, V.B.; Tupov, V.B.; Arkhipov, A.M.; Fomenko, M.V. Possible Ways of Reducing the Effect of Thermal Power Facilities on the Environment. Therm. Eng. 2015, 62, 146-153. [CrossRef]

40. International Organization for Standardization. ISO 14040: 2006, Environmental Management_Life Cycle Assessment-Principles and Framework; International Organization for Standardization: Geneva, Switzerland, 2006.

41. Tupov, V.B.; Taratorin, A.A. New steam silencers developed at MPÉI. Power Technol. Eng. 2015, 49, 301-303. [CrossRef]

42. International Organization for Standardization. ISO 1996-2: 1987 Acoustics-Description and Measurement of Environmental Noise_Part 2: Acquisition of Data Pertinent to Land Use; International Organization for Standardization: Geneva, Switzerland, 1987.

43. City of Lodz Office. Acoustic Map of the City of Lodz for 2017-2022. 2017. Available online: https:/ / mapa.lodz.pl/akustyczna (accessed on 20 May 2020). (In Polish).

44. GUS. Residential Conditions in Poland in 2017; Central Statistical Office: Warsaw, Poland, 2018.

45. World Health Organization. Burden of Disease from Environmental Noise. Quantification of Healthy Life Years Lost in Europe; The WHO European Centre for Environment and Health: Bonn, Germany, 2011.

46. Hischier, R.; Weidema, B.; Althaus, H.J.; Bauer, C.; Doka, G.; Dones, R.; Frischknecht, R.; Hellweg, S.; Humbert, S.; Jungbluth, N.; et al. Implementation of Life Cycle Impact Assessment Methods. Data v2.2. Ecoinvent Report No. 3. Dübendorf; Swiss Centre for Life Cycle Inventories: Dübendorf, Switzerland, 2010. 